\title{
Median Rhomboid Glossitis with a Kissing Lesion in the Palate: A Rare Case Report
}

\author{
Preeti Patil ${ }^{1}$, Karthik J Kabbur ${ }^{2}$, Ramnarayan B Krishnaprasad ${ }^{3}$, Sowbhagya M Basavaraju ${ }^{4}$
}

\begin{abstract}
Median rhomboid glossitis (MRG), also called central papillary atrophy of the tongue, was initially attributed to be a developmental disorder of the tongue that occurred due to the failure of tuberculum impar to withdraw before the union of the lateral halves of the tongue. However, now it is believed to be a lesion arising due to chronic candidal infection. Occasionally it may be associated with the erythematous lesion on the palate just opposing the tongue lesion, referred to as the kissing lesion. In this article we report a case of median rhomboid glossitis with a palatal kissing lesion in a 30-year-old male patient.

Keywords: Candidiasis, Central papillary atrophy, Kissing lesion, Median rhomboid glossitis.

Journal of Health Sciences \& Research (2019): 10.5005/jp-journals-10042-1080
\end{abstract}

\section{BACKGROUND}

Median rhomboid glossitis (MRG) is thought to be a congenital anomaly that occurs due to the persistent embryonic midline tongue structure, the tubercular impar. ${ }^{1}$ It is also known as central papillary atrophy (CPA) of the tongue, atrophy of the tongue papillae, median type (ATP) and localized atrophy of the tongue (LAT) papillae. ${ }^{2}$ The definite location of the lesion suggested that it was a developmental anomaly due to the persistence of the embryonic structure "tuberculum impar". However, it has now been considered as fungal infection caused by candidiasis. Median rhomboid glossitis manifests as a shiny oval or diamond-shaped depapillated area on the dorsal surface of the tongue in the midline just anterior to the circumvallate papillae. The prevalence of MRG in general population is less than $1 \%$ and ranges between $0.04 \%$ and $0.01 \%$ in the Indian population with males being more affected than females. ${ }^{3}$ Occasionally, there can be the presence of kissing lesion in the palate due to constant contact between the tongue lesion and the palate. In this article we present a case of MRG with a kissing lesion in the palate.

\section{Case Description}

A 30-year-old male patient reported to the department with complaints of pain in his upper right back teeth for a month. Pain was intermittent throbbing type and localized. It was his first dental visit. Medical and family history was noncontributory. Patient was moderately built and nourished. There was no extraoral abnormality. On intraoral examination, there was a deep carious lesion with 26 , which was tender on percussion. On examination of the tongue, a well-defined oval area of depapillation was present in the midline on the dorsal surface of the tongue. A similar erythematous lesion was seen on the palate just opposing the tongue lesion (Fig. 1). There were no other intraoral abnormalities. Provisional diagnosis of apical periodontitis, MRG with a kissing palatal lesion was made. Investigations included, complete blood count (CBC), intraoral periapical medical (IOPAR) with 26 and cytological smear from the tongue and palate.

The IOPA radiograph showed a chronic periapical abscess with 26, and $C B C$ was within the normal limit. Cytology from smears from the tongue and palate showed the presence of candidal
1,3 Department of Oral Medicine and Radiology, Dayananda Sagar College of Dental Sciences, Bengaluru, Karnataka, India

${ }^{2}$ Department of Orthodontics and Dentofacial Orthopaedics, Dayananda Sagar College of Dental Sciences, Bengaluru, Karnataka, India

${ }^{4}$ Department of Oral Medicine and Radiology, RajaRajeswari Dental College, Bengaluru, Karnataka, India

Corresponding Author: Preeti Patil, Department of Oral Medicine and Radiology, Dayananda Sagar College of Dental Sciences, Bengaluru, Karnataka, India, Phone: +919008369002, e-mail: pritipatil.4@gmail. com

How to cite this article: Patil P, Kabbur KJ, Krishnaprasad RB, et al. Median Rhomboid Glossitis with a Kissing Lesion in the Palate: A Rare Case Report. J Health Sci Res 2019;10(1):28-29.

Source of support: Nil

Conflict of interest: None

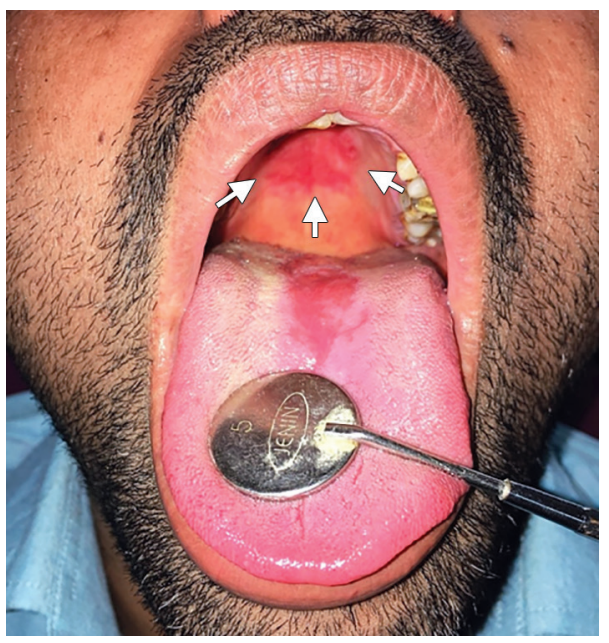

Fig. 1: Median rhomboid glossitis with the kissing lesion in the palate (white arrows)

() The Author(s). 2019 Open Access This article is distributed under the terms of the Creative Commons Attribution 4.0 International License (https://creativecommons. org/licenses/by-nc/4.0/), which permits unrestricted use, distribution, and non-commercial reproduction in any medium, provided you give appropriate credit to the original author(s) and the source, provide a link to the Creative Commons license, and indicate if changes were made. The Creative Commons Public Domain Dedication waiver (http://creativecommons.org/publicdomain/zero/1.0/) applies to the data made available in this article, unless otherwise stated. 
hyphae and desquamated epithelium. The patient was advised endodontic therapy with 26 . He was prescribed topical application of clotrimazole ointment and was instructed to apply it thrice a day and recalled after 2 weeks.

\section{Discussion}

Median rhomboid glossitis was initially believed to be a developmental abnormality caused by failure of tuberculum impar to withdraw before the union of the lateral halves of the tongue and subsequent failure of filiform papillae to develop in the dorsal tongue. However, MRG has not been reported in children. Hence, this lesion is now linked to a chronic infection by Candida albicans. ${ }^{4}$ Although most of the cases are asymptomatic, some patients complain of persistent pain, irritation, or pruritus. ${ }^{5}$ Occasionally, a similar lesion develops on the palate directly opposite the tongue lesion and is called a kissing lesion. It is more common in people with suppressed immunity and occurs due to transfer of fungal organisms from tongue to the palate during swallowing and other movements. When MRG is present along with the kissing palatal lesion, the patient should be investigated for immunosuppression. The lesion has been considered a marker of AIDS. ${ }^{6}$

The prevalence of MRG in the general population is less than $1 \%$ and varies between $0.04 \%$ and $0.01 \%$ in the Indian population, with males being more commonly affected than females. ${ }^{3}$ In a study conducted by Goregen on 4,244 patients, MRG was seen in $0.7 \%$ patients and only three patients with MRG had the kissing lesion. ${ }^{7}$

Bihari et al. reported a case of MRG with the kissing lesion in the palate in a 24-year-old male patient. The patient presented with complaints of burning sensation in the tongue and had erythematous lesion on the dorsal surface of the tongue. Multiple erythematous lesions were seen in the palate opposing the tongue lesion. ${ }^{8}$

Suvarna et al. reported a case of MRG with a kissing lesion in palate in a 62-year-old male patient who had a history of burning sensation in the palate for 7 years. ${ }^{9}$ Galletta et al. reported a case of hyperplastic candidiasis on the palate developed as a "kissing" lesion from MRG in a 41 -year-old male patient. ${ }^{10}$ In the present case the patient was asymptomatic and was unaware of the lesion.

Diagnosis of MRG is mainly clinical, although histopathology may be required for differential diagnosis. Role of Candida can be proved by isolation of Candida from the lesion by laboratory techniques such as smear, culture on Sabouraud's dextrose agar, colony forming units etc. In the present case cytological smear was positive for candidal hyphae. Similar results were obtained in previous studies which showed the presence of candidal hyphae in the cytology. ${ }^{8-10}$ The lesion is usually treated by antifungal drugs followed by periodic reevaluations of the patient. Full remission of the lesion after antifungal therapy confirms the candidal infection.

\section{Conclusion}

Median rhomboid glossitis along with the kissing lesion in the palate is uncommon. When present, immunosuppression has to be suspected and necessary investigations have to be advised for proper diagnosis and management of the patient.

\section{References}

1. Silverman S, Eversole LR, Truelove EL. Essentials of oral medicine. In: Developmental mucosal conditions. London: BC Decker Inc Hamilton; 2001. pp. 255-256.

2. Mehta FS, Bhonsle RB, Murti PR, et al. Central papillary atrophy of the tongue among bidi smokers in india; a 10-year study of 182 lesions. J Oral Pathol Med 1989;18(8):475-480. DOI: 10.1111/j.1600-0714.1989. tb01346.x.

3. Bojan A, Christy W, Kurian K, et al. A study to determine the association between tobacco smoking habit and oral candidal infection in median rhomboid glossitis by cytologic and histopathological method. J Indian Aca Oral Med Radiol 2012;24(2):106-112. DOI: 10.5005/jp-journals-10011-1272.

4. Zegarelli DJ. Fungal infections of the oral cavity. Otolaryngol Clin North Am 1993;26(6):1069-1089.

5. Joseph BK, Savage NW. Tongue pathology. Clin Dermatol 2000;18(5):613-618. DOI: 10.1016/S0738-081X(00)00137-1.

6. Rogers RS, Bruce AJ. The tongue in clinical diagnosis. J Eur Acad Dermatol Venereol 2004;18(3):254-259. DOI: 10.1111/j.1468-3083. 2004.00769.x.

7. Goregen M, Miloglu O, Buyukkurt MC, et al. Median rhomboid glossitis: a clinical and microbiological study. Eur J Dent 2011;5(4): 367-372. DOI: 10.1055/s-0039-1698907.

8. Bihari M, Srivastava R, Jyoti B, et al. Median rhomboid glossitis with palatal 'kissing lesion'- a case report. Bangladesh J Dental Res \& Educ 2014;4(2):94-97. DOI: 10.3329/bjdre.v4i2.20273.

9. Suvarna R, Rao PK, Kini R, et al. Vidya holla kissing lesion-from tongue to the palate. MOJ Surg 2018;6(1):17-18

10. Galletta VC, Campos MS, Hirota SK, et al. Hyperplastic candidosis on the palate developed as a 'kissing' lesion from median rhomboid glossitis. Braz J Otorhinolaryngol 2010;76(1):137. DOI: 10.1590/S180886942010000100023. 